\title{
ANALISIS SISTEM PENATAAN DAN TEMU BALIK ARSIP INAKTIF DI DINAS PANGAN, TANAMAN PANGAN DAN HORTIKULTURA PROVINSI RIAU
}

\author{
Yetti Nur Ngazizah*), Rismayeti**), Hadira Latiar***) \\ Jurusan Ilmu Perpustakaan, Fakultas Ilmu Budaya, Universitas Lancang Kuning, \\ Pekanbaru, Indonesia \\ email: yetti_nur@yahoo.co.id*), rismayeti@gmail.com**), hadiralatiar6@gmail.com***)
}

Naskah diterima: 2 April 2021; direvisi: 10 Juni 2021; disetujui: 28 Juni 2021

\begin{abstract}
Abstrak
Penelitian ini bertujuan untuk mengetahui bagaimana sistem penataan dan temu balik arsip inaktif di Dinas Pangan, Tanaman Pangan dan Hortikultura Provinsi Riau. Metode yang digunakan dalam penelitian ini yaitu metode analisis data deskriptif. Adapun teknik analisis data yang dilakukan peneliti yaitu reduksi data, penyajian data dan penarikan kesimpulan. Sedangkan untuk temu balik arsip mengacu pada perhitungan recallprecision. Populasi penelitian yaitu seluruh staff Sub Bagian Umum dan Kepegawaian yang berjumlah 25 orang dan arsip inaktif tahun 2015 yang berjumlah 327 arsip. Sampel penelitian yaitu 1 orang staff honorer sub bagian umum dan kepegawaian dan 2 arsiparis penyelia dan arsiparis ahli muda, peneliti mengambil 3 informan yang langsung berkaitan dengan penataan arsip inaktif. Sampel arsip yang digunakan untuk temu balik arsip yaitu dengan menggunakan 8 kata kunci dengan kode klasifikasi arsip yaitu 005 (Undangan), 048 (Pengelolaan Data), 822 (Kenaikan Gaji Berkala), 823 (Kenaikan Pangkat), 842 (Dana), 851 (Cuti Tahunan), 855 (Cuti naik haji/umroh), 862 (Hukuman). Hasil penelitian menunjukkan sistem penataan arsip inaktif di Dinas Pangan, Tanaman Pangan dan Hortikultura Provinsi Riau yaitu menggunakan pedoman berdasarkan Peraturan Kepala Arsip Nasional Republik Indonesia Nomor 4 Tahun 2017 dan temu balik arsip inaktif menggunakan aplikasi Ms.Excel dan daftar arsip inaktif. Rata-rata nilai perolehan (recall) sebesar 97,75\% dan rata-rata tingkat ketepatan (precision) yang dihasilkan sebesar 99,05\%. Jadi, penataan arsip inaktif cukup baik dan untuk recall precision arsip menunjukkan hasil persentase tidak seimbang dikarenakan beberapa faktor yaitu masih adanya arsip yang belum diinput serta masih terdapat arsip yang tidak sesuai dengan kata kunci yang digunakan.
\end{abstract}

Kata kunci: Arsip inaktif, Penataan arsip inaktif, temu balik arsip, recall precision

\begin{abstract}
This study aims to determine how the system of structuring and retrieval of inactive archives in the Department of Food, Crops and Horticulture Riau Province. The method used in this study is descriptive data analysis method. The data analysis techniques carried out by researchers are data reduction, data presentation and conclusion drawing. Meanwhile, archive retrieval refers to the calculation of recall-precision. The research population is all staff of the General and Civil Service Sub-Division who opened 25 people and inactive archives in 2015 which opened 327 archives. The research sample is 1 honorary staff of the general and civil service sub-section and 2 supervisory archivists and young expert archivists, researchers took 3 informants who were directly related to the arrangement of inactive archives. The archive sample used for archive retrieval is by using 8 keywords with archive classification codes, namely 005 (Invitation), 048 (Data Management), 822 (Regular Salary Increase), 823 (Raise), 842 (Funds), 851 (Annual
\end{abstract}


Leave), 855 (Leave for Hajj/Umrah), 862 (Penalty). The results showed that the inactive archive arrangement system at the Food, Food Crops and Horticulture Department of Riau Province was using guidelines based on the Regulation of the Head of the National Archives of the Republic of Indonesia Number 4 of 2017 and inactive archive retrieval using the Ms. The average recall value is $97.75 \%$ and the average recall level is $99.05 \%$. So, the arrangement of inactive archives is quite good and to remember the precision of the archive shows the results of an unbalanced proportion due to several factors, namely there are still archives that have not been inputted and there are still archives that do not match the keywords used.

Keywords: inactive archives, inactive archive arrangement, archive retrieval, recall precision

\section{PENDAHULUAN}

Setiap lembaga baik lembaga pemerintahan maupun swasta pastinya memerlukan data serta informasi, salah satunya adalah arsip. Kegiatan administrasi akan berpengaruh pada pencapaian tujuan yang hendak dicapai. Pada umumnya semakin lama organisasi atau kantor beroperasi, maka akan semakin banyak pula volume arsip dalam kegiatan administrasi tersebut. Seiring dengan bertambahnya volume arsip yang dimiliki serta tidak adanya penanganan arsip, maka arsip hanya akan menjadi tumpukan kertas maupun gambar yang tidak memiliki nilai guna maupun manfaat.

Pengertian arsip telah diatur dalam Undang-Undang Nomor 43 tahun 2009, arsip merupakan rekaman kegiatan atau peristiwa dalam berbagai bentuk dan media sesuai dengan perkembangan teknologi informasi dan komunikasi yang dibuat dan diterima oleh lembaga negara, pemerintahan daerah, lembaga pendidikan, perusahaan, organisasi politik, organisasi kemasyarakatan, dan perseorangan dalam pelaksanaan kehidupan bermasyarakat, berbangsa, dan bernegara.

Kearsipan memegang peranan penting bagi kelancaran suatu organisasi ataupun instansi pemerintahan, yaitu sebagai sumber dan pusat informasi bagi setiap instansi ataupun organisasi. Salah satu kegiatan utama dari kearsipan yaitu melakukan penyimpanan informasi secara sistematis agar arsip terpelihara dengan baik dan mudah ditemukan ketika dibutuhkan suatu saat nanti.

Pengelolaan arsip yang baik akan memudahkan dalam penemuan kembali arsip. Penemuan kembali arsip ini berhubungan dengan sistem penataan yang dipilih oleh suatu lembaga. Sistem penataan arsip ini terdiri dari beberapa macam yang disesuaikan dengan kebutuhan suatu lembaga.Sistem penataan arsip yang dipilih dapat menjadi ciri khas dari suatu lembaga karena perbedaan arsip yang diolah.

Permasalahan pengelolaan arsip juga terjadi di Dinas Pangan, Tanaman Pangan dan Hortikultura Provinsi Riau. Arsip yang terdapat di dinas tersebut terus bertambah seiring waktu berjalan sehingga diperlukan sistem penataan arsip yang baik. Masalah yang lain timbul yaitu sarana prasarana yang kurang memadai serta kurangnya ruangan untuk menampung kenaikan volume arsip yang bertambah setiap tahunnya. Berdasarkan data terakhir tahun 2015 jumlah arsip inaktif yang berada di Dinas Pangan, Tanaman Pangan dan Hortikultura berjumlah 327 arsip (Sumber:Daftar Arsip Inaktif tahun 2015). Dengan bertambahnya volume arsip setiap tahunnya maka akan berdampak pada proses penemuan kembali arsip yang akan memakan waktu lama dalam penemuannya.

Berdasarkan uraian di atas, penulis tertarik untuk melakukan penelitian dan pengkajian lebih lanjut mengenai sistem 
penataan dan temu balik arsip inaktif, yang kemudian dituangkan kedalam judul Analisis Sistem Penataan dan Temu Balik Arsip Inaktif di Dinas Pangan, Tanaman Pangan dan Hortikultura Provinsi Riau.

Ada beberapa penelitian yang membahas tentang sistem penataan dan temu balik arsip inaktif, namun penulis hanya mengambil beberapa penelitian yang sesuai dengan judul dan dibutuhkan oleh penulis diantaranya :

Pertama, penelitian yang ditulis oleh (Latiar, 2019) dengan judul "Efektifitas Sistem Temu Kembali Arsip Digital Universitas Lancang Kuning Pekanbaru". Penelitian ini bertujuan untuk mengetahui bagaimana tingkat keefektifan software digital arsip 2.0.0 dari segi recall-precision sebagai sarana sistem temu balik arsip digital Universitas Lancang Kuning. Penelitian ini menggunakan metode kualitatif dengan menganalisis data. Hasil penelitian menunjukkan bahwa nilai recall memperoleh hasil cukup tinggi sedangkan nilai precision juga cukup tinggi, tetapi jumlah dokumen relevan yang ditemukan di lemari arsip menurun.

Kedua, penelitian yang ditulis oleh (Fitriana \& Christiani, 2018) dengan judul "Tata Kelola Penyimpanan Arsip Dinamis Aktif Dalam Upaya Meningkatkan Efisiensi Penemuan Kembali Arsip Di Dinas Kearsipan Dan Perpustakaan Kabupaten Pati". Penelitian ini bertujuan untuk mengetahui tata kelola penyimpanan arsip da lam upaya meningkatkan efisiensi penemuan kembali arsip di Dinas Kearsipan dan Perpustakaan Kabupaten Pati. Metode yang digunakan dalam penelitian ini adalah metode penelitian kualitatif deskriptif dengan pendekatan studi kasus. Hasil penelitian ini menunjukan bahwa tata kelola penyimpanan arsip dinamis aktif merupakan upaya untuk meningkatkan efisiensi penemuan kembali arsip di Dinas Kearsipan dan Perpustakaan Kabupaten Pati. Implementasi pengelolaan arsip dinamis aktif di Dinas Kearsipan dan Perpustakaan Kabupaten Pati dimulai dari tahap penciptaan, penggunaan, pemeliharaan serta penyusutan arsip yang telah dilakukan secara tertib dan berurutan. Tata kelola penyimpanan arsip dinamis aktif di Dinas Kearsipan dan Perpustakaan Kabupaten Pati mengacu pada faktor-faktor kearsipan yang baik yaitu penggunaan sistem penyimpanan yang tepat, fasilitas kearsipan dan petugas kearsipan yang memenuhi syarat.

Ketiga, penelitian yang ditulis oleh (Wasdiana \& Setyadi, 2017) dengan judul "Analisis Sistem Penyimpanan Dan Temu Balik Arsip Inaktif Berkas Perkara Di Pengadilan Negeri Ungaran". Tujuan penelitian ini adalah untuk mengetahui sistem penyimpanan dan temu balik Arsip Inaktif Berkas Perkara di PN Ungaran.Penelitian ini menggunakan metode deksriptif kualitatif dengan informan berjumlah 5 orang terdiri dari Pengelola Arsip dan Pengguna Arsip Inaktif Berkas Perkara yang dipilih dengan metode purposive sampling.Analisis data menggunakan teknik reduksi data yang disertai dengan analisis domain, penyajian data dan penarikan kesimpulan. Hasil penelitian menunjukkan sistem penyimpanan Arsip Inaktif Berkas Perkara yang digunakan adalah sistem subjek,sistem kronologi, sistem nomor dan sistem warna. Temu balik Arsip Inaktif Berkas Perkara dilakukan dengan cara manual dengan berbantuan klasifikasi subjek dan buku register, dan dengan berbantuan komputer melalui database Ms. Excel.

Kemudian sebagaimana yang telah dikemukakan diatas, adapun pengertian mengenai sistem penataan arsip menurut (Sedarmayanti, 2015) yang dimaksud dengan sistem penataan arsip atau archief system (Bahasa Belanda), atau biasa juga disebut dengan filling system (Bahasa Inggris) adalah kegiatan mengatuur dan menyusun arsip dalam suatu tatanan yang sistematis dan logis, menyimpan serta merawat arsip untuk digunakan secara aman dan ekonomis.

Sedangkan menurut Peraturan Kepala Arsip Nasional Republik Indonesia Nomor 4 Tahun 2017 mengatakan bahwa 
penataan arsip inaktif adalah penataan arsip inaktif pada unit kearsipan melalui kegiatan pengaturan fisik arsip, pengolahan informasi arsip dan penyusunan daftar arsip inaktif. Hal ini senada dengan penjelasan terkait penataan arsip inaktif menurut Peraturan Arsip Nasional republik Indonesia Nomor 9 Tahun 2018 yang mengatakan bahwa penataan arsip inaktif pada unit kearsipan dilaksanakan melalui prosedur pengaturan fisik arsip, pengolahan informasi arsip dan penyusunan daftar arsip inaktif.

Tahapan Penataan arsip menurut Peraturan Kepala Arsip Nasional Republik Indonesia Nomor 4 Tahun 2017 yaitu:

1. Memeriksa

2. Mendeskripsi

3. Menyortir

4. Menempatkan arsip dalam folder

5. Memberi nomor definitif

6. Menata folder dalam boks

7. Membuat daftar arsip inaktif

8. Membuat skema lokasi simpan;dan

9. Melakukan penyimpanan arsip inaktif.

Sistem penataan arsip sangat erat hubungannya terhadap keberhasilan penemuan kembali arsip tersebut, karena jika sistem penataannya kurang baik maka akan berpengaruh terhadap proses penemuan arsip yang sulit dan memakan waktu yang lama dalam penemuannya.

Menurut Ibrahim (2013:69) dalam (Wahyuddin, 2017) mengemukakan bahwa sistem temu balik informasi merupakan proses yang berhubungan dengan representasi, penyimpanan, pencarian dengan pemanggilan onformasi relevan dengan kebutuhan informasi yang diinginkan pengguna. Untuk mengukur efektifitas dari suatu sistem sebuah sistem temu balik informasi tersebut, maka dilakukan pengukuran efektifitas tersebut menggunakan rumus recall precision arsip.

Menurut Sulistyo Basuki (1991) dalam (Latiar, 2019) menjelaskan dalam sebuah sistem dapat dinilai rasio perolehan (recall) yaitu dengan membandingkan dokumen yang terpanggil dengan total dokumen relevan yang disimpan dalam sistem, untuk memperoleh rasio ketepatan (precision) yaitu membandingkan dokumen relevan dengan total dokumen/informasi dalam penelusuran.

Menurut Hasugian (2006) dalam (Latiar, 2019) mengatakan bahwa perhitungan nilai recall dan precision menggunakan persamaan sebagai berikut :

Recall = Total item relevan disistem $\mathrm{x}$ $100 \%$

Total dokumen yang dimilki

Precision $=$ Total item relevan dirak $\mathrm{x}$ $100 \%$

Total item yang relevan disistem

Dalam merumuskan matriks sebagai ukuran nilai recall-precision bisa dilihat pada tabel dibawah ini:

Tabel 1. Ukuran Recall-Precision

\begin{tabular}{|l|l|l|l|}
\hline & Relevan & $\begin{array}{c}\text { Tidak } \\
\text { Relevan }\end{array}$ & Total \\
\hline $\begin{array}{l}\text { Ditem } \\
\text { ukan }\end{array}$ & $\mathrm{a}$ (hits) & $\mathrm{b}($ noise $)$ & $\mathrm{a}+\mathrm{b}$ \\
\hline $\begin{array}{l}\text { Tidak } \\
\text { Ditem } \\
\text { ukan }\end{array}$ & $\mathrm{c}$ (mises) & $\begin{array}{l}\mathrm{d}(\text { rejected } \\
\mathrm{j}\end{array}$ & $\mathrm{c}+\mathrm{d}$ \\
\hline Total & $\mathrm{a}+\mathrm{c}$ & $\mathrm{b}+\mathrm{d}$ & $\begin{array}{l}\mathrm{a}+\mathrm{b}+ \\
\mathrm{c}+\mathrm{d}\end{array}$ \\
\hline
\end{tabular}

Sumber menurut (Pendit,2007) dalam (Latiar, 2019)

Dari informasi tabel diatas, persamaan recall precision menjadi:

$\begin{array}{ll}\text { Recall } & =[\mathrm{a} /(\mathrm{a}+\mathrm{c})] \times 100 \\ \text { Precision } & =[\mathrm{a} /(\mathrm{a}+\mathrm{b})] \times 100\end{array}$

Melalui rumus tersebut dapat dikatakan bahwa sebuah sistem pengindeksan harus meningkatkan recall dengan memperbesar nilai a(hits). Pada nilai a(hits) memperoleh nilai besar dapat 
terjadi jika jumlah dokumen yang terpanggil $(a+c)$ oleh sistem juga besar. Semakin besar jumlah dokumen yang terpanggil $(\mathrm{a}+\mathrm{c})$ semakin besar pula kemungkinan nilai a(hits). Tetapi pada saat yang sama muncul kemungkinan bahwa nilai b jumlah dokumen yang tidak relevan juga semakin besar, artinya nilai precision semakin kecil. Dalam berbagai uji penilaian recall-precision sebagian besar berlawanan, yang mana jika perolehan dokumen/informasi (recall) mendapat nilai tinggi, maka kemungkinan besar nilai ketepatan (precision) rendah.

\section{METODE PENELITIAN}

Metode yang digunakan dalam penelitian ini adalah metode penelitian menggunakan penelitian deskriptif kualitatif untuk mengetahui sistem penataan dan temu balik arsip inaktif. Pada penelitian ini penulis melakukan observasi untuk mengambil data awal penelitian agar mengetahui bagaimana sistem penataan serta mengetahui hasil recall-precision arsip tersebut. Selanjutnya penulis melakukan wawancara terhadap pihak yang mengelola kearsipan didinas tersebut sebagai pemberi informasi untuk mengambil data berupa rekaman, lalu penulis mengambil beberapa dokumentasi sebagai pelengkap dari metode observasi dan wawancara.

Sedangkan dalam metode analisis data menggunakan reduksi data lalu data yang diperoleh dijabarkan dan selanjutnya dilakukan penarikan kesimpulan serta menggunakan persamaan recall-precision untuk menjawab bagaimana temu balik arsip inaktif didinas tersebut.

Populasi dalam penelitian ini adalah seluruh staff Subbag Umum dan Kepegawaian yang berjumlah 25 orang yang terdiri dari 16 tenaga ASN dan 9 orang THL. Selanjutnya populasi dalam penelitian ini adalah jumlah arsip inaktif tahun 2015 yang berjumlah 327 arsip (sumber : Subbag Umum dan Kepegawaian:2020)

Sebagai sampel dan penguat dalam penelitian ini, penulis mengambil informan yang langsung berkaitan dengan sistem penataan dan temu balik arsip yaitu berjumlah 3 orang. Ada beberapa syarat dalam pengambilan sampel ini yakni sebagai berikut :

a. Petugas dan pengguna arsip di Dinas Pangan, Tanaman Pangan dan hortikultura

b. Pernah melaksanakan kegiatan pengelolaan arsip inaktif di Dinas Pangan, Tanaman Pangan dan Hortikultura.

c. Pernah melakukan pengertian arsip.

d. Petugas dan pengguna arsip yang bersedia diwawancarai.

e. Mampu berkomunikasi dengan baik dan mampu memberikan informasi yang relevan tentang objek penelitian.

Ssampel arsip pada penelitian ini yaitu menggunakan kata kunci dengan kode klasifikasi 005 (undangan), 048 (Pengelolaan data), 822 (Kenaikan Gaji Berkala), 823 (Kenaikan Pangkat), 842 (Dana), 851 (Cuti Tahunan), 855 (Cuti Naik Haji/Umroh), 862 (Hukuman).

\section{HASIL DAN PEMBAHASAN}

Dari penelitian yang telah dilakukan, diperoleh beberapa temuan hasil pengamatan dan wawancara sebagai berikut:

a) Dinas pangan, Tanaman Pangan dan Hortikultura Provinsi Riau telah melakukan tahapan penataan arsip inaktif sesuai dengan pedoman berdasarkan Peraturan kepala Arsip Nasional Republik Indonesia Nomor 4 Tahun 2017. Namun dari seluruh tahapan yang mereka gunakan ditemukan adanya temuan terkait tahapan penataan yang tidak mereka lakukan yaitu tidak terdapat adanya peta lokasi atau pemetaan lokasi simpan yang digunakan sebagai petunjuk arah terkait penyimpanan arsip tersebut hanya saja untuk penerapan skema lokasi simpan yang dimaksud mereka hanya melakukan pelaksaann dilapangan saja seperti menyusun arsip berbaris dari kiri kekanan sesuai nomor kode klasifikasi arsip tersebut

b) Sistem penyimpanan yang digunakan yaitu sistem penyimpanan berdasarkan nomor dan pokok permasalahan, 
sedangkan untuk proses temu balik arsip menggunakan Daftar Pertelaan Arsip (DPA) serta alat bantu komputer melalui database MS.Excel.

c) Ditemukan adanya beberapa berkas yang tidak ditemukan pada lemari arsip ketika ditelusuri dan ditemukan adanya berkas yang tidak sesuai dengan nomor kode klasifikasi yang serupa.

Untuk mengetahui bagaimana recallprecision pada sistem temu balik arsip inaktif pada Ms.Excel di Dinas Pangan, Tanaman Pangan dan Hortikultura Provinsi Riau, maka penulis mengolah dan menganalisis data dibawah ini mengacu pada rumus yang telah dipaparkan sebelumnya:

Tabel 1. Hasil Perhitungan RecallPrecision

\begin{tabular}{|c|c|l|l|l|l|l|}
\hline $\begin{array}{c}\text { Rele } \\
\text { van }\end{array}$ & $\begin{array}{c}\text { Tid } \\
\text { ak } \\
\text { Rel } \\
\text { eva } \\
\text { n }\end{array}$ & $\begin{array}{c}\text { T } \\
\text { ot } \\
\text { al }\end{array}$ & $\begin{array}{c}\text { Tid } \\
\text { ak } \\
\text { dit } \\
\text { em } \\
\text { uka } \\
\text { n }\end{array}$ & $\begin{array}{c}\text { T } \\
\text { ot } \\
\text { al }\end{array}$ & $\begin{array}{c}\text { Rec } \\
\text { all }\end{array}$ & $\begin{array}{c}\text { Preci } \\
\text { sion }\end{array}$ \\
\hline 4 & 0 & 4 & 0 & 4 & 100 & 100 \\
\hline 8 & 0 & 8 & 0 & 8 & 100 & 100 \\
\hline 2 & 0 & 2 & 0 & 2 & 100 & 100 \\
\hline 5 & 0 & 5 & 1 & 6 & 83. & 100 \\
\hline 3 & 0 & 3 & 0 & 3 & 100 & 100 \\
\hline 148 & 2 & 1 & 2 & 1 & 98. & 98.67 \\
& & 5 & & 5 & 67 & \\
\hline 4 & 0 & 4 & 0 & 4 & 100 & 100 \\
\hline 60 & 44 & 6 & 0 & 6 & 100 & 93.75 \\
& & 4 & & 0 & & \\
\hline & & & & & & \\
& & & & & & \\
\hline
\end{tabular}

Sumber : Data diolah pada tanggal 22-032021

Dari tabel di atas maka didapatkan rata-rata nilai precision adalah sebesar 99,05\% dan nilai recall-nya adalah sebesar $97,75 \%$ dari skala $0 \%-100 \%$, sehingga dapat dikatakan bahwa nilai precision lebih tinggi dari pada nilai recall berdasarkan kata kunci yang digunakan dalam pencarian temu kembali arsip di Dinas Pangan, Tanaman Pangan dan Hortikultura tersebut.Dari beberapa kata kunci yang dicari, kata kunci yang nilai recall dan precision yang tinggi terdapat pada kata kunci “005, 048, 822, 842 dan 855", yang nilai precison dan recall -nya adalah $100 \%$. Sedangkan perbandingan nilai recall lebih besar dari pada nilai precision (recall>precision) sebanyak 1 kata kunci. Dan terdapat pula perbandingan nilai recall sama dengan nilai precision (recall = precision) sebanyak 1 kata kunci serta terdapat perbandingan nilai precision lebih besar dibanding nilai recall (precision>recall) sebanyak 1 kata kunci. Dimana dapat dikatakan bahwa semakin tinggi nilai precison maka semakin efektif sebuah sistem tersebut.

Untuk proses penemuan kembali arsip yang dilakukan di Dinas Pangan, Tanaman Pangan dan Hortikultura Provinsi Riau dilakukan dengan menggunakan daftar arsip inaktif serta menggunakan alat bantu kopmuter melalui database di Ms.Excel. Waktu yang dibutuhkan dalam penemuann kembali arsip inaktif yaitu tidak lebih dari 5 menit untuk 1 jenis arsip. Waktu pencarian arsip sudah termasuk cepat dan mudah ditemukan.

\section{Kendala - Kendala dalam kegiatan penataan dan temu balik arsip}

Selanjutnya, untuk mengetahui kendala yang ditemukan dalam melakukan kegiatan penataan dan penyimpanan arsip inaktif di Dinas Pangan, Tanaman Pangan dan Hortikultura Provinsi Riau, penulis melakukan wawancara dengan arsiparis yang menangani hal tersebut yakni informan I:

"Kalau untuk kendala dalam melakukan kegiatan penataan arsip inaktif di sini palingan sarana dan prasarana seharusnyakan bertambah sarana dan prasarananya karna kan arsip tiap tahun bertambah juga volume nya. Kalau untuk SDM masih kurang juga untuk arsiparis hanya berdua dan untuk pelaksanaan dilapangan kami masih keteteran juga dan itupun kami kebantu ketika ada anak magang yang membantu. Seharusnya itukan SDM ahli 2 orang sedangkan sekarang hanya 1 orang dan untuk SDM penyelia hanya 1 orang" 
Berdasarkan uraian diatas, adapun kendala yang ditemukan yaitu kurangnya sarana dan prasarana dan kurangnya sumber daya manusia. Seiring perkembangan zaman, jumlah arsip yang setiap tahun bertambah maka sangat penting untuk dilakukannya penambahan atau penyesuaian sarana dan prasarana yang dibutuhkan agar dalam melakukan penataan arsip lebih baik lagi kedepannya dan arsip dapat tertata dengan baik. Selanjutnya untuk sumber daya manusia masih dibutuhkannya beberapa arsiparis yang mengelola arsip tersebut, karena sumber daya manusia memiliki peran yang penting dalam melakukan pengelolaan arsip dengan bertambahnya arsip setiap tahun maka masih dibutuhkannya penanganan yang lebih khusus dan fokus terhadap arsip yang ada serta dibutuhkannya SDM yang berkompeten dibidang kearsipan, agar arsip yang dikelola dapat disimpan dengan baik dan lebih mudah dalam penemuan kembali.

\section{PENUTUP}

Dari hasil penelitian saya, dapat disimpulkan bahwa :

1. Sistem penataan arsip inaktif di Dinas Pangan, Tanaman Pangan dan Hortikultura menggunakan sistem nomor dan pokok permasalahan arsip, hal tersebut dikatakan sudah baik karena telah sesuai dengan pedoman berdasarkan Peraturan Kepala Arsip Nasional Republik Indonesia Nomor 4 Tahun 2017 namun dari seluruh tahapan yang mereka gunakan ditemukan adanya temuan terkait tahapan penataan yang tidak mereka lakukan. Sistem nomor yang dimaksud yaitu berdasarkan nomor kode klasifikasi arsip dan untuk sistem pokok permasalahn yang digunakan yaitu berdasarkan pokok

\section{DAFTAR PUSTAKA}

Fitriana, E. D., \& Christiani, L. (2018). Tata Kelola Penyimpanan Arsip Dinamis Aktif Dalam Upaya Meningkatkan Efisiensi Penemuan Kembali Arsip Di Dinas Kearsipan Dan Perpustakaan Kabupaten Pati. Jurnal Ilmu Perpustakaan, 7(3), 151-160. permasalahan yang ada atau berdasarkan subject arsip yang ada didinas tersebut seperti cuti tahunan, undangan serta permasalahan terkait kenaikan pangkat dll.

2. Berdasarkan hasil penelitian terkait sistem temu balik arsip inaktif di Dinas Pangan, Tanaman Pangan dan Hortikultura Provinsi Riau masih menggunakan metode manual melalui daftar arsip inaktif dan dibantu dengan komputer melalui database Ms.Excel. selanjutnya dapat dikatakan bahwa tingkat efektivitas temu kembali menggunakan aplikasi Ms.Ecxel sudah bisa dikatakan efektif. Hal ini terlihat dari rata-rata tingkat perolehan (recall) sebesar $97,75 \%$ dan rata-rata tingkat ketepatan (precision) yang dihasilkan sebesar 99,05 dari sejumlah kata kunci yang dicari, kata kunci dengan nilai recall dan precison sebesar $100 \%$ yaitu kata kunci 005, 048, 822, 842 dan 855. Hal tersebut dikarenakan jumlah yang relevan lebih besar atau seimbang, hal ini juga membuktikan bahwa nilai recall dan precison tinggi karena sistem dapat mengendalikan kumpulan kata kunci berdasarkan nomor klasifikai sistem penataan yang digunakan. Sedangkan yang mempunyai nilai precison yang paling rendah yaitu dengan kata kunci "862" yang nilai recall sebesar 100\% dan precision sebesar $93.75 \%$. Hal tersebut dikarenakan jumlah dokumen relevan yang ditemukan menurun atau tidak seimbang dari jumlah dokumen yang terpanggil. Hal tersebut menunjukkan bahwa aplikasi Ms. Excel menunjukkan tampilan yang cukup baik, namun dalam hal penyusunan dokumen masih kurang baik.

$$
\begin{aligned}
& \text { Retrieved from } \\
& \text { https://ejournal3.undip.ac.id/index.p } \\
& \text { hp/jip/article/view/22928 }
\end{aligned}
$$

Latiar, H. (2019). Efektifitas Sistem Temu Kembali Arsip Digital Universitas Lancang Kuning Pekanbaru. Jurnal Pustaka Budaya, 6(1), 9-15. https://doi.org/10.31849/pb.v6i1.21 31 
Sedarmayanti.

(2015).

Tata Kearsipan;Dengan Memanfaatkan Teknologi Modern. Bandung: CV.Manda Maju.

wahyuddin. (2017). Pemanfaatan sistem temu balik informasi di dinas perpustakaan dan kearsipan kabupaten barru skripsi. 13.
Wasdiana, M. D., \& Setyadi, A. (2017). Analisis Sistem Penyimpanan Dan Temu Balik Arsip Inaktif Berkas Perkara Di Pengadilan Negeri Ungaran. Jurnal Ilmu Perpustakaan, 6(3), 341-350. Retrieved from https://ejournal3.undip.ac.id/index.p hp/jip/article/view/23164 